\title{
Analysis the Prevalence of Trichomonas vaginalis in Women Clinics of Tehran City's Referents by PCR
}

\author{
Safayi delouyi Z. ${ }^{1} M S c$, Valadkhani Z.* PhD, Sohrabi M. ${ }^{2}$ PhD \\ *Parasitology Department, Pasteur Institute of Iran, Tehran, Iran \\ ${ }_{1}^{1}$ Microbiology Department, Basic Sciences Faculty, Qom Branch, Islamic Azad University, Qom, Iran \\ ${ }^{2}$ Biology Department, Basic Sciences Faculty, Qom Branch, Islamic Azad University, Qom, Iran
}

\begin{abstract}
Aims: Trichomoniasis is the most common sexually-transmitted disease in the world. This study aimed to investigate the prevalence of Trichomonas vaginalis by PCR referred to the women clinics of Tehran City.

Materials \& Methods: This cross-sectional study was done on 140 women admitted to Tehran Loghman and Shahid Shoorideh clinics hospital from November 2013 to December 2014. Demographic data were collected by a questionnaire. Using 2 swabs, from the posterior fornix of the vagina, secretions were collected with a swab to examine in the vaginal TYI-S-33 culture and another for molecular detection placed in a tube containing $2 \mathrm{ml}$ of sterile saline and transferred to the laboratory. Data were analyzed by SPSS 11 and One-sample T test.

Findings: Of 46 suspected patients with Trichomonas vaginalis infection, vaginal secretions of $11(7.8 \%)$ patients and urine samples of $4(2.8 \%)$ patients by PCR, vaginal secretions of $6(4.2 \%)$ and urine sample of $1(0.5 \%)$ were reported positive in culture. There was a significant correlation between education and husbands' job and Trichomonas vaginalis infection $(\mathrm{p}<0.05)$. There was not a significant correlation between contraception and prevalence of Trichomonas vaginalis ( $\mathrm{p}>0.05$ ).

Conclusion: Employing new molecular methods based on PCR is recommended as a supplement or alternative to current methods for detection of Trichomonas vaginalis.
\end{abstract}

Keywords

Trichomonas Vaginalis [http://www.ncbi.nlm.nih.gov/mesh/68014246];

Prevalence [http://www.ncbi.nlm.nih.gov/mesh/68015995];

Diagnosis [http://www.ncbi.nlm.nih.gov/mesh/68003933];

Polymerase Chain Reaction [http://www.ncbi.nlm.nih.gov/mesh/68016133]

\footnotetext{
* Corresponding Author

Tel: +982164112267

Fax: +982166968855

Address: Parasitology Department, Pasteur Institute of Iran, $12^{\text {th }}$ of Farvardin Street, Tehran, Iran valad.zarrin@gmail.com

Received: July 8, 2014 
مواج و عامل بيمارى تريكومونيازيس، شايعترين بيمارى

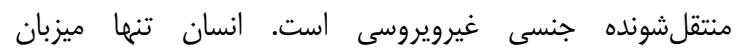

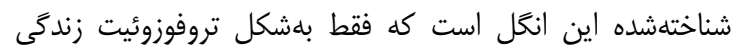

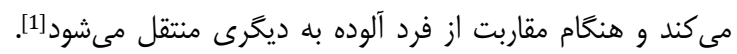

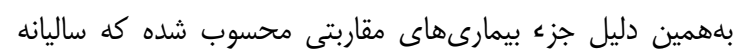
• ^اميليون نفر در جهان را به مبتلا مى كند [2].

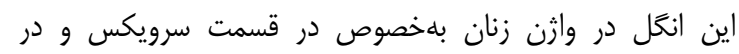

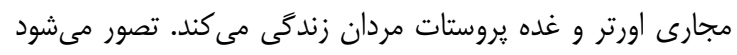

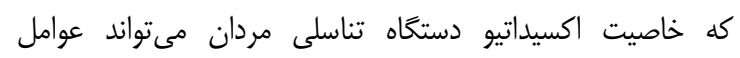

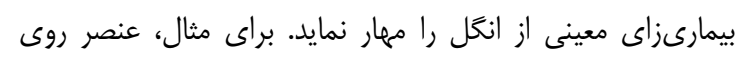

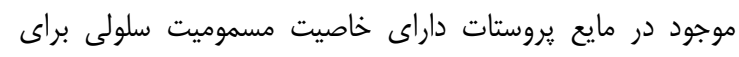

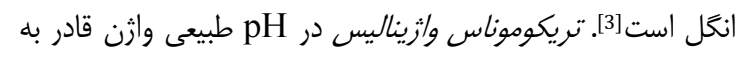

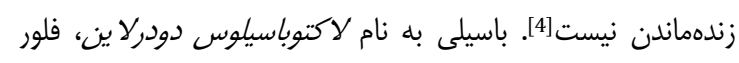

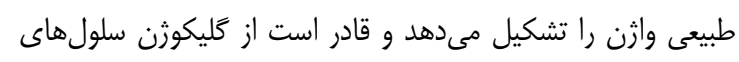

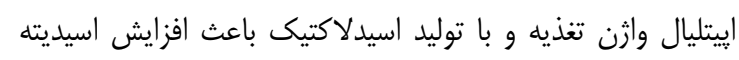

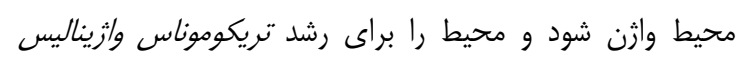
نامساعد سازد. با افزايش تعداد لاكتوباسيلوسها، مواد غذايى وازثن مصرف شده و

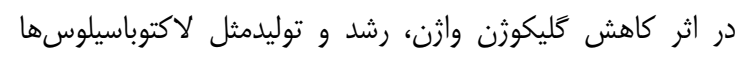

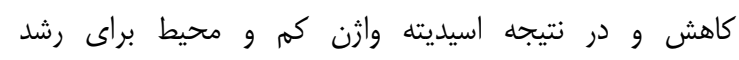

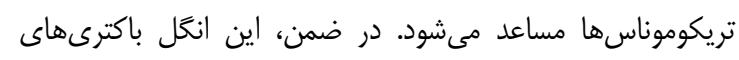

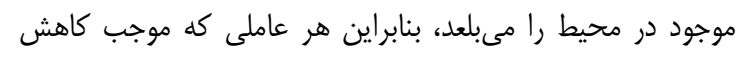

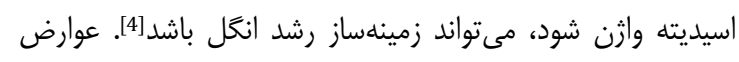

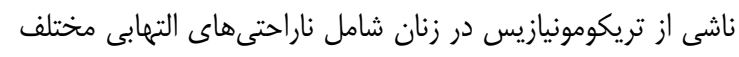

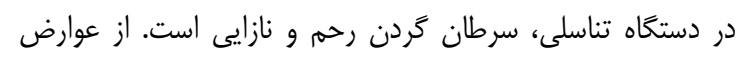

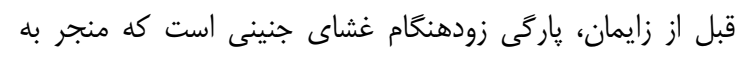

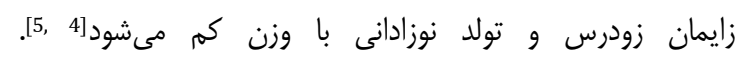

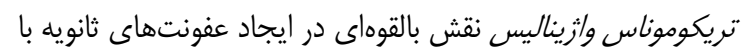
ويروس نقص ايمنى اكتسابى و ويروس بإيبلوماى انسانى دارد [6].

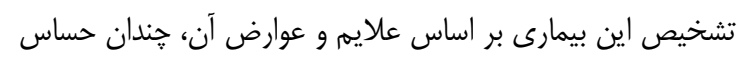

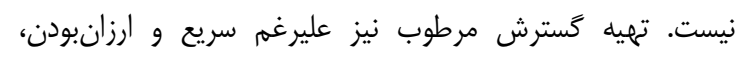

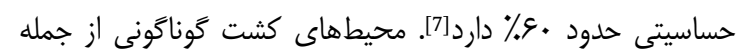

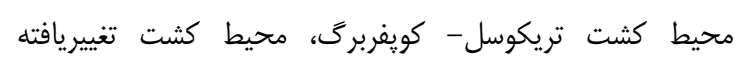

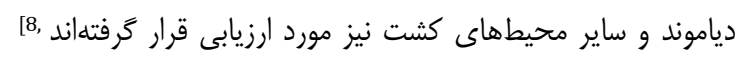

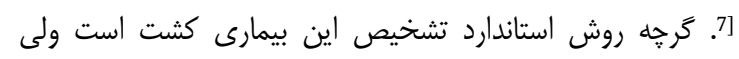

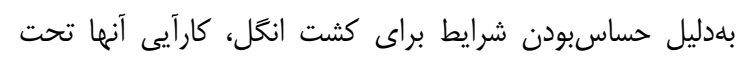

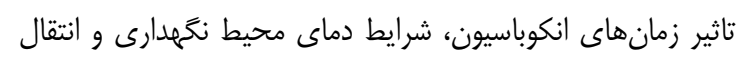

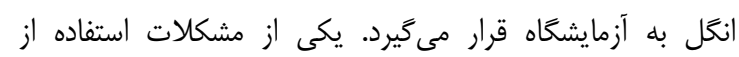

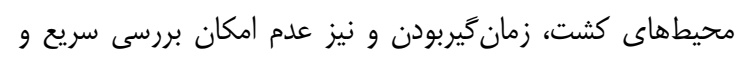

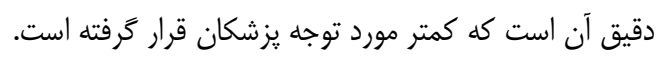

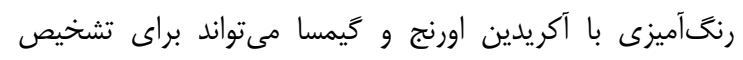

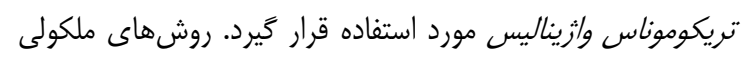

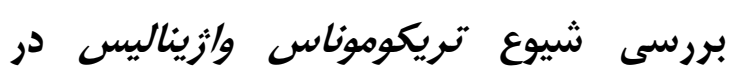

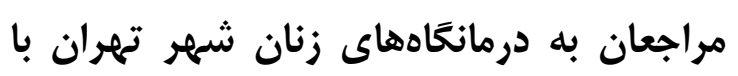
واكنش زنجيرهاي يليمرازى درمانى

زهرا صفايي دلويى MSc كَروه ميكروبيولوزى، دانشكده علوم بايه، واحد قم، دانشخاه آزاد اسلامى، قمه، ايران

زرين تاج ولدخانى " زيرن كروه انكلششناسى، انستيتو ياستور ايران، تهران، ايران

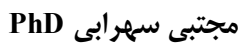

كرووه زيستشناسى، دانشكده علوم هايه، واحد قم، دانشكاه آزاد اسلامى، قهم، ايران

جكيده

اهداف: تريكومونيازيس، شايعترين بيمارى منتقلشونده از طريق جنسى

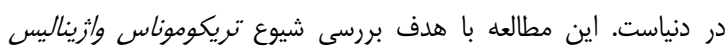

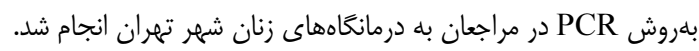

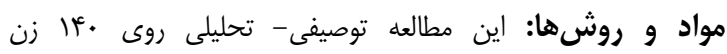

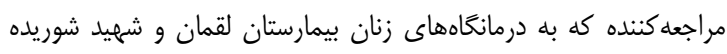

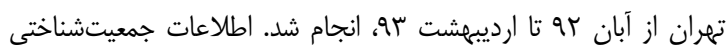

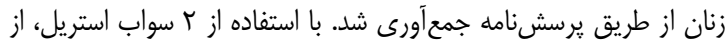

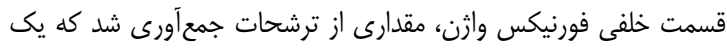

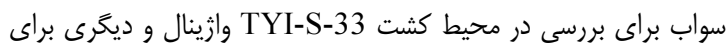

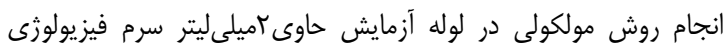

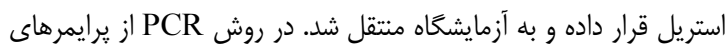

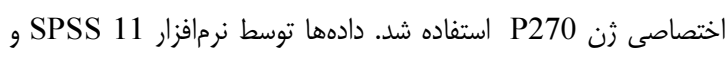

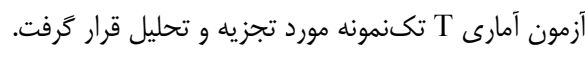

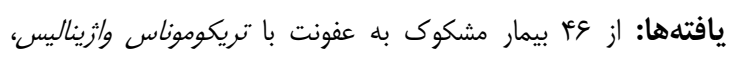

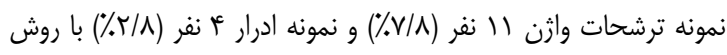

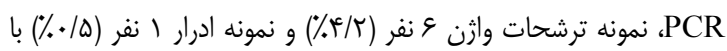

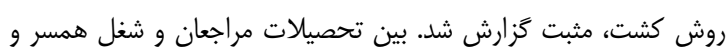

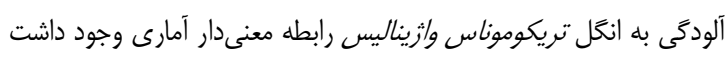

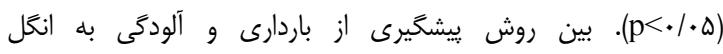

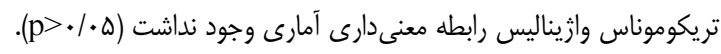

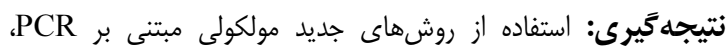

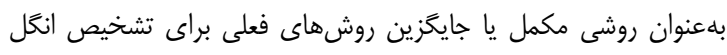

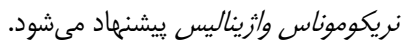

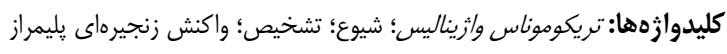

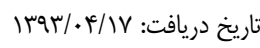

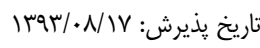
valad.zarrin@gmail.com :تويسنده مسئول:

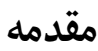

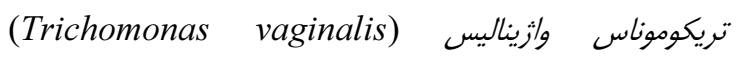
تكياختهاى متحرى با ههار تازك، يك هسته قدامى و يكى يرده

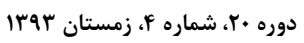

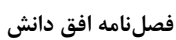




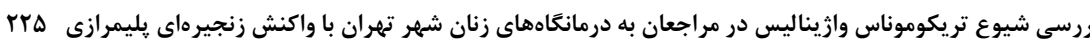

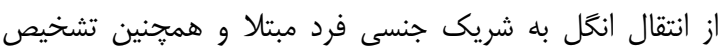

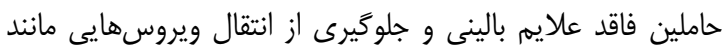
روش تشخيص دقيقى مانند PCR ضرورى به نظر مىرسد. اين مطالعه با هدف بررسى شيوع تريكوموناس واثزيناليس بلروش

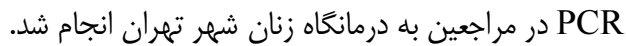

\section{مواد و روشها}

اين مطالعه توصيفى - تحليلى روى زنانى كه به درمانگاههاى زنان

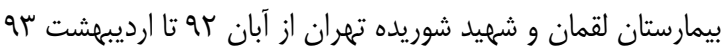

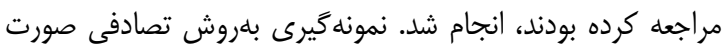

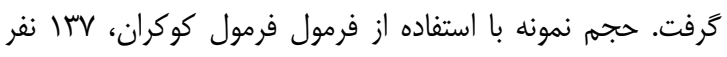

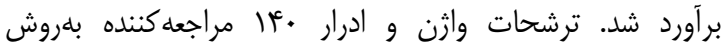

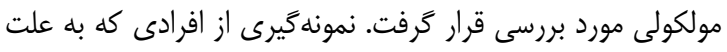

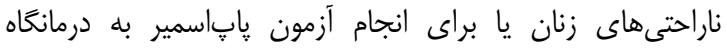

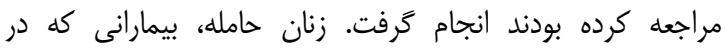
^أساعت منتهى به مطالعه از داروهاى موضعى استفاده كرده بودند و نيز زنانى كه در دوران عادت ماهيانه بودند از مطالعه حذف شدان مداند.

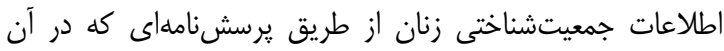

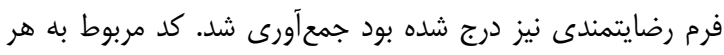

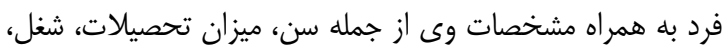
شغل همسر، سابقه سقط، روش ييشخيرى از باردارى، تشخيص

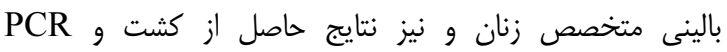
بلهتكيك ثبت شد. درضمن شماره تماسى نيز از آنان دريافت شد زلان

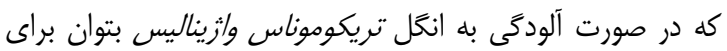

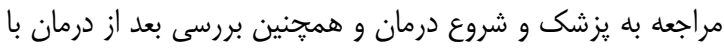
آنان تماس كرفته شود. نمونه ادرار بيماران در لولههاى فالكون استريل (هاميلى لئليتر) ريخته

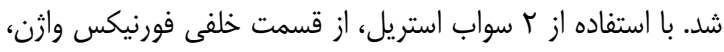

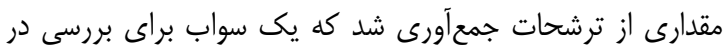

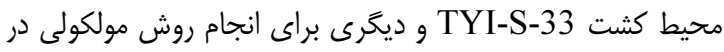

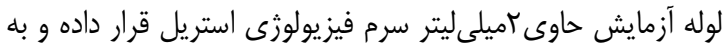

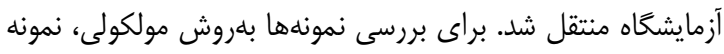

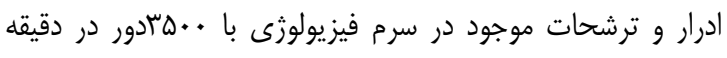

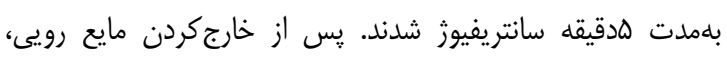
رسوب آنها براى استخراج DNA و انجام روش

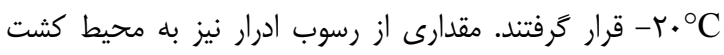
اضافه شد. محيطهاى كشت حاوى نمونههاى بيماران داخل

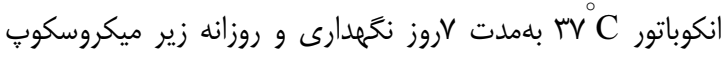

معكوس مشاهده مىشد [5].

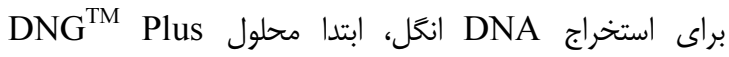

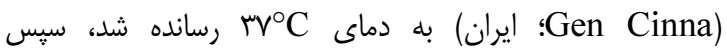

مبتنى بر PCR براى تشخيص تريكومونيازيس با حساسيت و

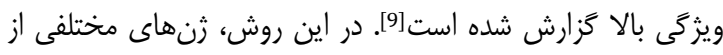

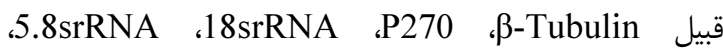

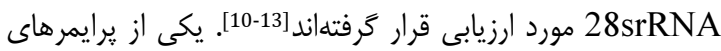

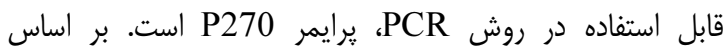
اطلاعات موجود، تا به حال در ايران استفاده از اين يرايمر خزارش راش

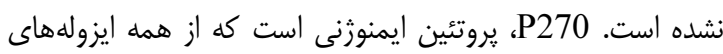
مورد بررسى گزارش شده است [13].

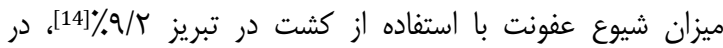

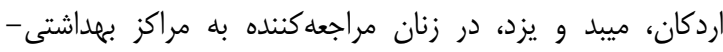

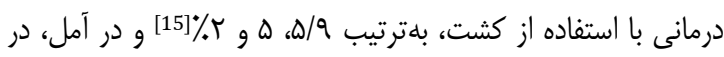

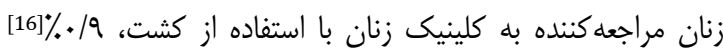

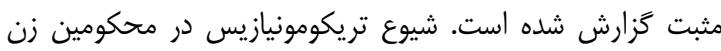

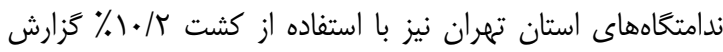

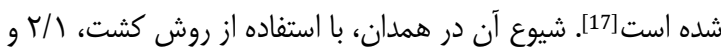

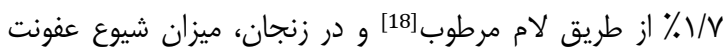

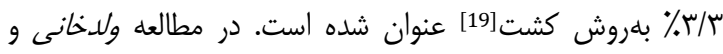

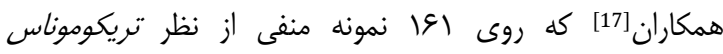
وازيناليس بلروشهاى كشت و لام مستقيم انجام شده است، با

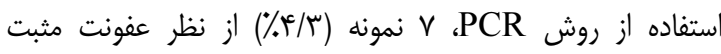

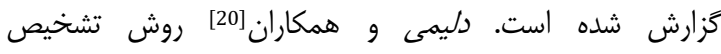
تريكوموناس واثزيناليس با استفاده از تكثير ثن ا ا داراى حساسيت بالا گزارش نمودهاند. PCR

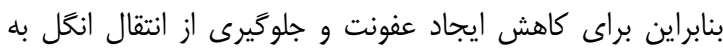

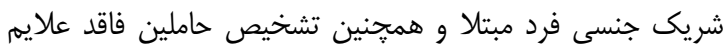

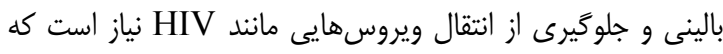

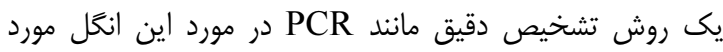

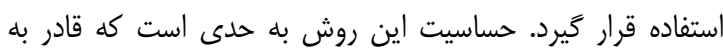

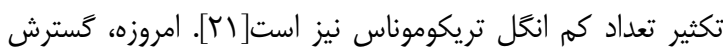

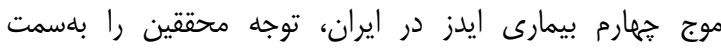
بيمارىهاى منتقلشونده از طريق روابط جنسى معطوف كرده است. اين موج كه تلفيقى از روابط جنسى ناسالم و تزريق مشترك است، مسئولين حوزه سلامت را به تكايو انداخته است. به ديه دليل اينكه تريكوموناس و/ثيناليس با بلعيدن ميكروفلوراهاى طبيعى واثن باعث افزايش pH محيط مىشود و در نتيجه كاهش ميكروفلوراها، راديكالهاى آزاد محيط كاهش مىيابد، لذا باعث مناسبط مئدن شرايط محيط در انتقال ويروس HIV و در نتيجه بيمارى ايدز

$$
\text { مىشود [22]. - مئ. }
$$

تاكنون مطالعات زيادى در جهان و ايران روى اين تكىياخته انجام شده است. با توجه به شيوع آلودگى به اين انغل در در ايران، انجان انجام

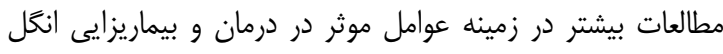

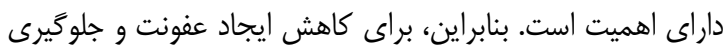




\section{يافتهها}

وثا بيمار در زمان معاينات بالينى توسط يزشك مشكوك به عفونت

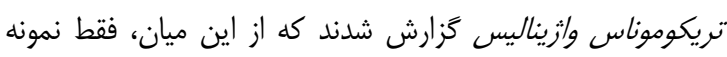

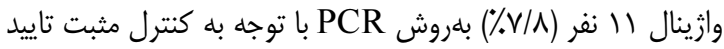

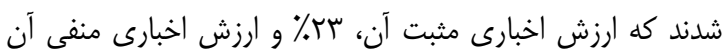
مها هV محاسبه شد. حساسيت روش PCR محاسبه شد. در بيمارانى كه نمونه ادرار آنها مثبت كزارش شده بود، مثبتبودن

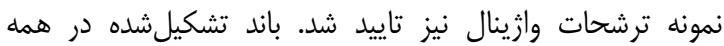
نمونهها داراى وزن VTrكيلوباز بوال بود (شكل ().

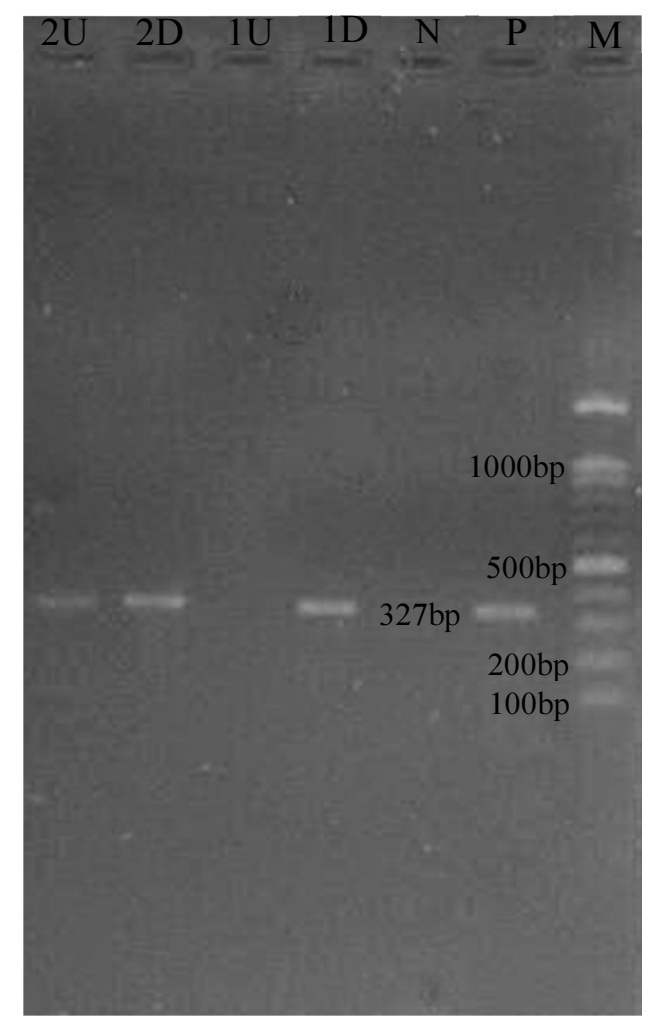

شكل () بيمار شماره ا داراى ترشح واثن مثبت و نمونه ادرار منفى بود. نمونه

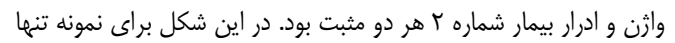

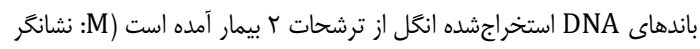

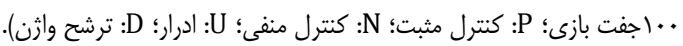

شايعترين علامت بيماران مبتلا به تريكومونيازيس خارش و ترشح

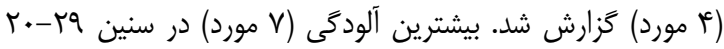

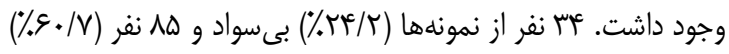

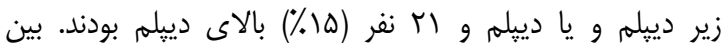

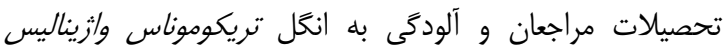

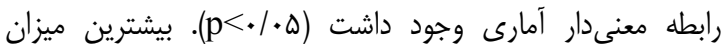

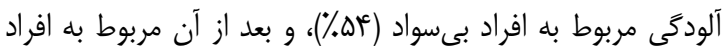

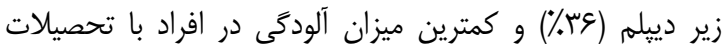

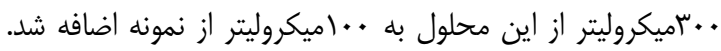

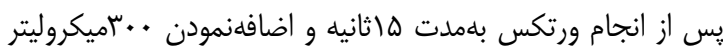

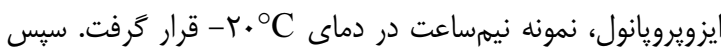

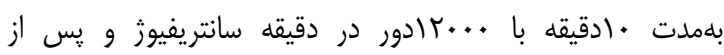

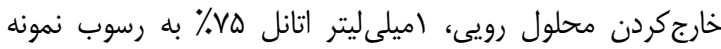

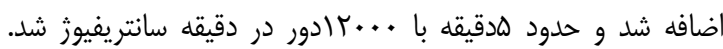

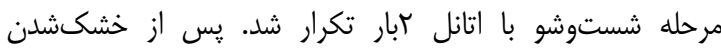

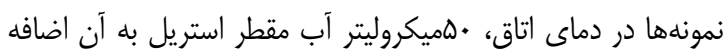

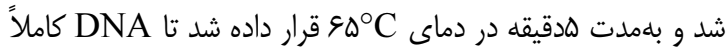

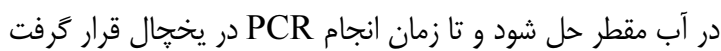

براى آزمايش نمونهها بلروش PCR از جفت يرايمرهاى خن

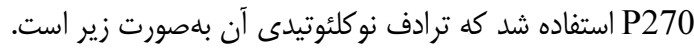
رفت: رقي برَشت: CTTGAGATTTCTTGCAAAACACAAAGT واكنشهاى PCR در حجم •"سميكروليتر انجام شدند كه شامل

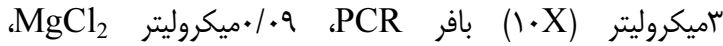

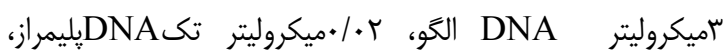

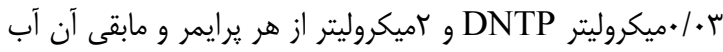

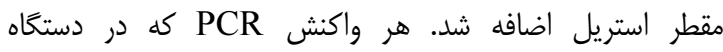
ترموسايكلر (Bio-RAD)؛ ايالات متحده) انجام شد، شامل •"آرخه بود؛ بيش از קرخه اصلى، يكى مرحله انكوباسيون در $9{ }^{\circ} \mathrm{C}$ بdمدت هدقيقه انجام شد. واسرشت در

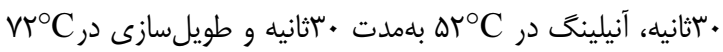

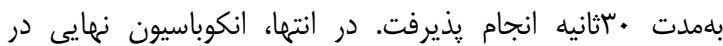
هدقيقه در دماى VI V انجام شد.

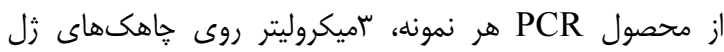

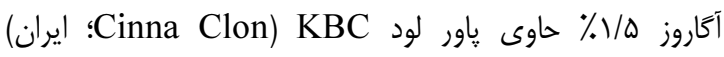
الكتروفورز شد. الكتروفورز در بافر تريس- استات اتيلندى آمين آنارين (TAE)

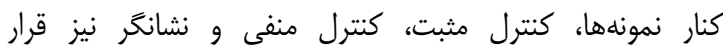

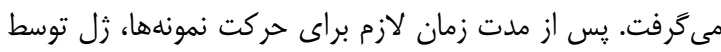
دستخاه زلداكت بررسى و عكسبردارى مدار شد.

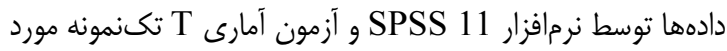
تجزيه و تحليل قرار كرفت. براى تعيين حساسيت از فرمول تقسيم إنماري

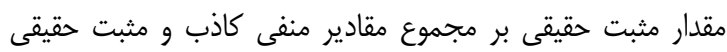

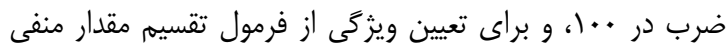

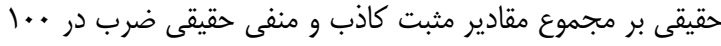

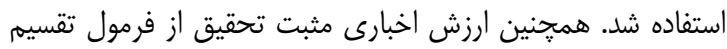

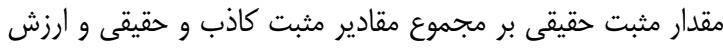

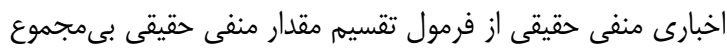
مقادير منفى كاذب و حقيقى محاسبه شدند. 


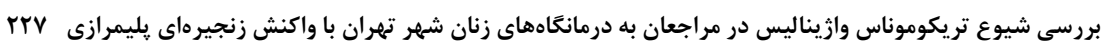

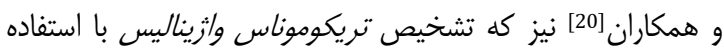
از تكثير زن 18srRNA بلروش PCR انجام شده است اين

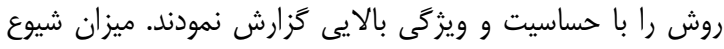

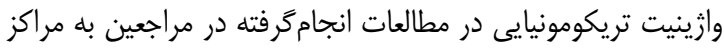

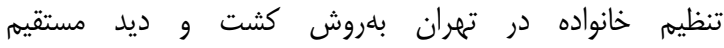

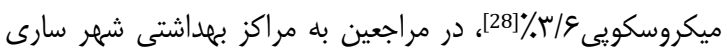

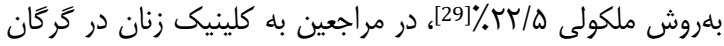

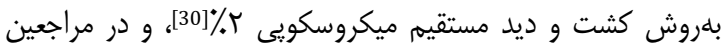

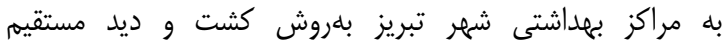

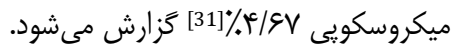

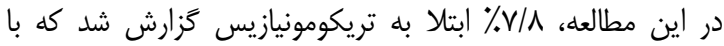
توجه به نوع روش مورد استفاده و جامعه مورد مطالعه با ساير

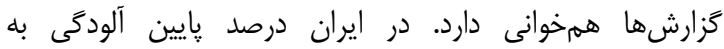

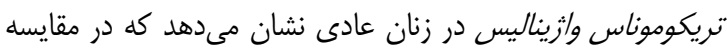
با ديخر كشورها، گسترش اين بيمارى از سطح پايينترى برخوردار

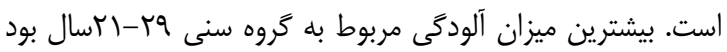

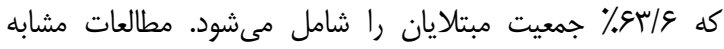

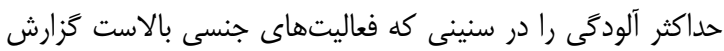

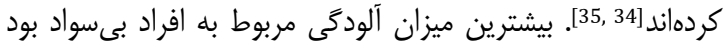

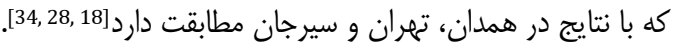

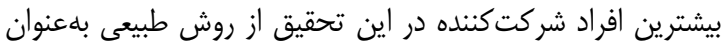

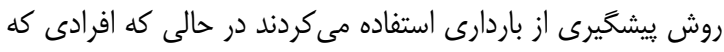

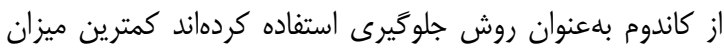

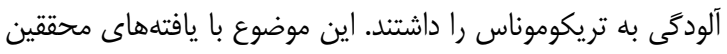
قبلى همخوانى دارد [35,34]. تحقيقات انجامشده در مركز يزشكى داردى كلرادو نشان مىدهد درد خانمهايى كه براى جلوگيرى از باردارى، همسرانشان از كاندوم

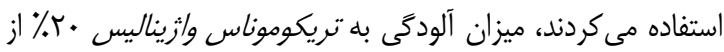

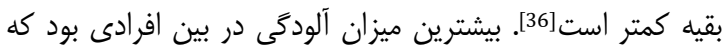

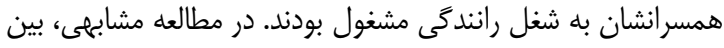
شغل همسر و آلودخى با تريكوموناس وازريناليس رابطه معنى دئدار آمارى ديده مىشود و در افرادى كه همسرانشان كاركر هستند

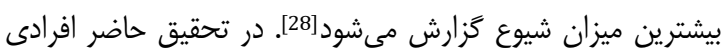

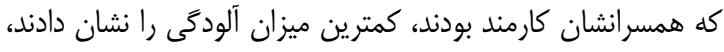
كه شايد علت آن آكًاهىهاى بهداشتى افراد تحصيل كردهد باشد.

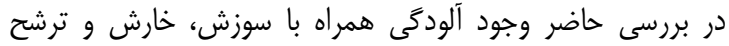
ارتباط معنىدار آمارى داشت. طبق تحقيقات مشابه كه در سيرجان و تهران انجام شده است، از نظر علايم بالينى بين سوزش، خارش و

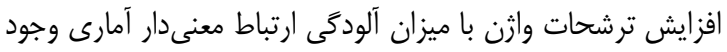
داردم [34, 28. باتوجه به عوارض ناشى از آلودگى زنان به تريكومونيازيس بلخصوص در دوران باردارى، تشخيص سريع و درمان بلموقع

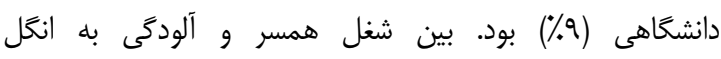

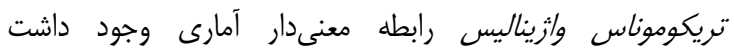

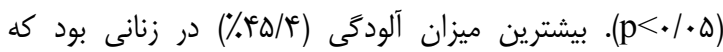

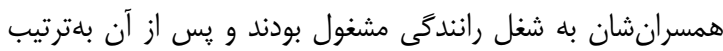

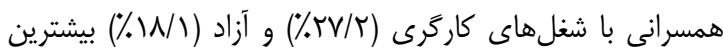

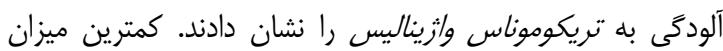

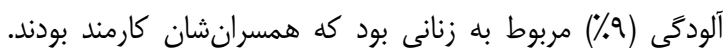

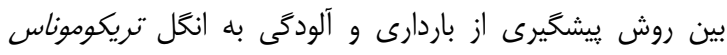

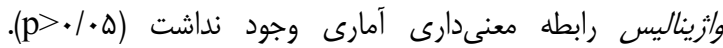

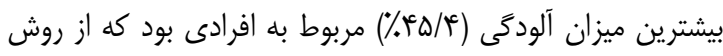
طبيعى استفاده مى كردند.

\section{بحث}

عفونت تريكومونيازيس در تمام نقاط دنيا شيوع دارد. ميزان شيوع

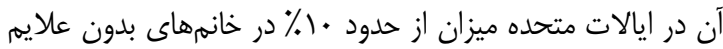

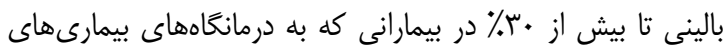

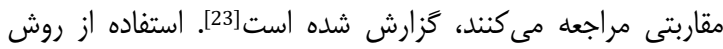

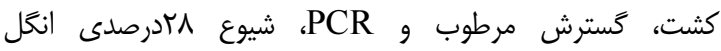
تريكوموناس واثيناليس در ترشحات وازينال، از نمونههاى ادرار و

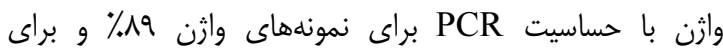

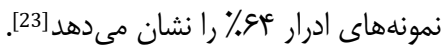
در مطالعه آنورلاو همكاران نيز، در خانمهاى داراى علايمم بالينى تريكومونيازيس، شيوع هادرصدى عفونت به روش كشت گزارش

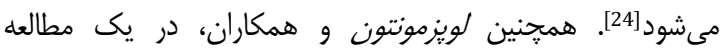
مقطعى از مar ror بيمار براى شناسايى تريكوموناس واثريناليس بلهروش PCR تريكوموناس وازيناليس اعلام گزارش شده است [25].

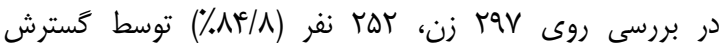

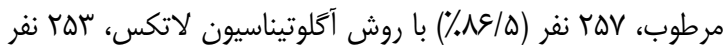

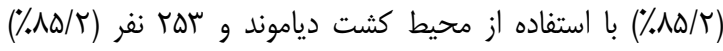
بلهروش PCR براى تريكوموناس واززيناليس مثبت كزارش شدهاند[7]. مقايسه نتايج ذكرشده با نتايج مطالعه حاضر نشان

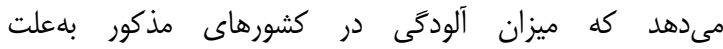
بىبندوبارىهاى جنسى، استفاده از شريكهاى جنسى متعدد و و وجود مراكز فساد، در سطح بالايى نسبت به ايران قرار دارد.

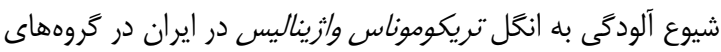

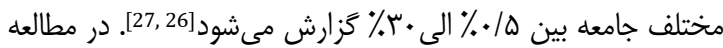

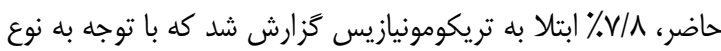

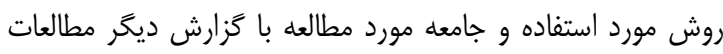

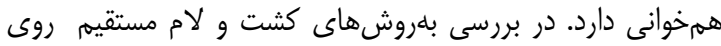

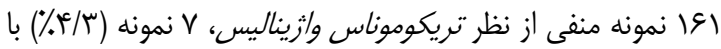

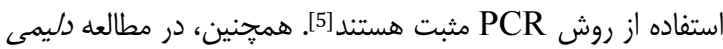


مى شود نمونه ترشحات وازينال زنان مراجعلكننده به درمانكاههاى

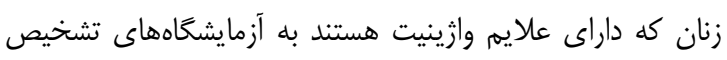

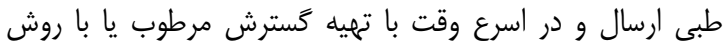
PCR مورد مطالعه قرار كيرند.

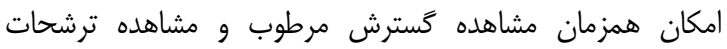
وارينال بيمارانى كه شك بالينى به تريكومونيازيس براى آنها وجود

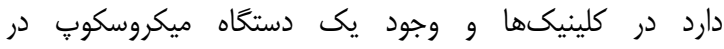

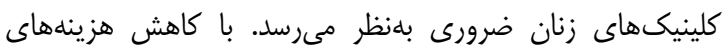

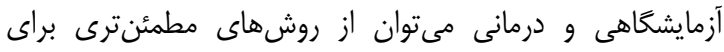

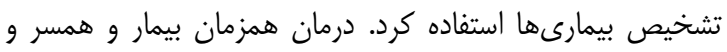
دقت در يافتههاى فيزيكى و توجه به شكايات بيمار ضرورى است

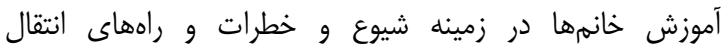

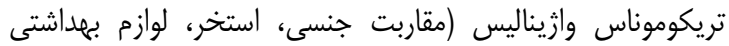

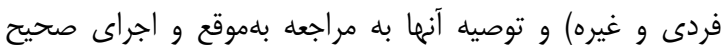

$$
\text { درمان ييشنهاد مى شود. }
$$

\section{نتيجل كيرى}

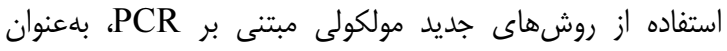
روشى مكمل و يا جايخزين روشهاى فعلى براى تشخيص انغل

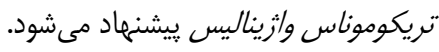

تشكر و قدردانى: اين مطالعه بخشى از پايانانامه بوده كه با

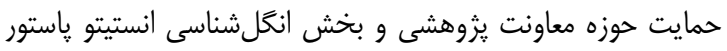

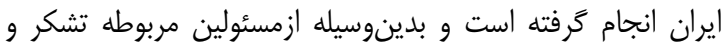

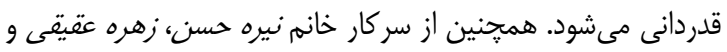

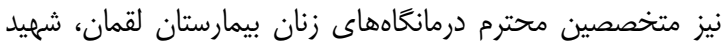
شوريده و بيمارانى كه در انجام اين تحقيق همكارى نمودند تقدير و

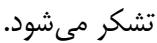
تاييديد اخلاقى: مطالعات شيوع جون بلهصورت مداخلهاى نيستند

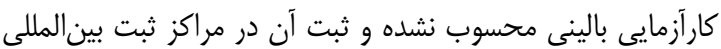

$$
\text { كارآزمايى بالينى ضرورى نيست. }
$$

تعارض منافع: موردى توسط نويسندكان مطرح نشده است.

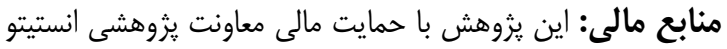

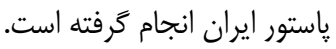

\section{منابع}

1- Ovalle A, Martínez MA, de la Fuente F, Falcon N, Feliú F, Fuentealba F, et al. Prevalence of sexually transmitted infections in pregnant women attending a public hospital in Chile. Rev Chilena Infectol. 2012;29(5):517-20.

2- Queza MI, Rivera WL. Diagnosis and molecular characterization of Trichomonas vaginalis in sex workers in the Philippines. Pathog Glob Health. 2013;107(3):136-40.

3- Pattman RS. Recalcitrant vaginal trichomoniasis. Sex Transm Infect. 1999;75(2):127-8.

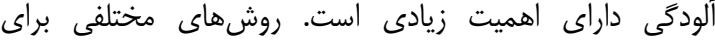

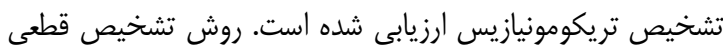

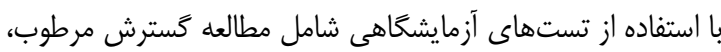

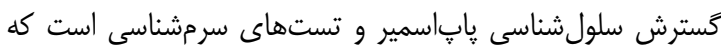
حساسيت كمترى نسبت بله روشهاى مولكولى داسلى دارند [32].

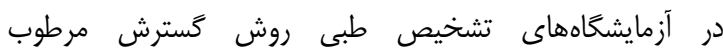

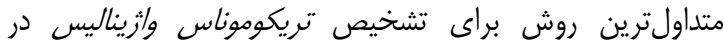

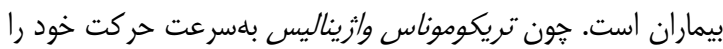

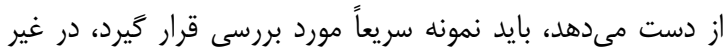

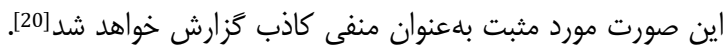

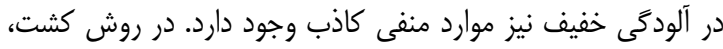

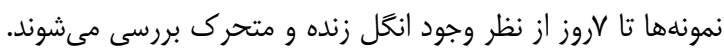

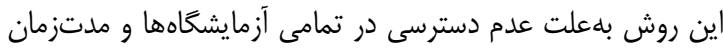

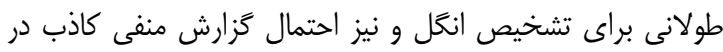

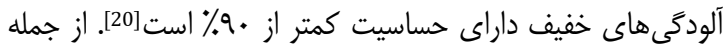

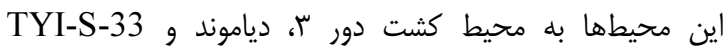
مىتوان اشاره نمود كه از جمله روشهاى مورد تاييد در تشخيص

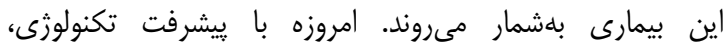
روشهاى مولكولى در تشخيص و تعيين هويت انكلها كه حتى انغكل غيرزنده و معيوب هم قابل شناسايى است كاربردهاى فراونى تُانى

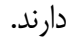

در مطالعات انجامشده توسط محققين مختلف اين مزيتها بلوضوح

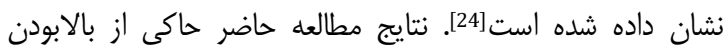
حساسيت و ويثگى روش PCR در مقايسه با تشخيص كلينيكى

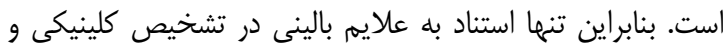

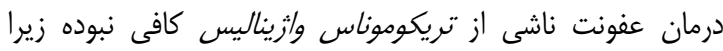

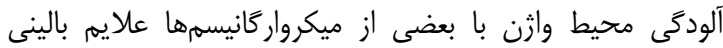

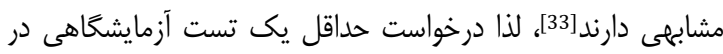

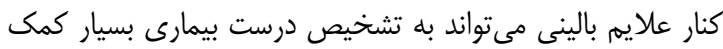

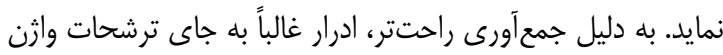

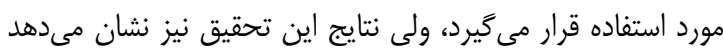

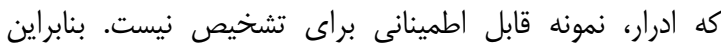

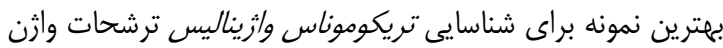

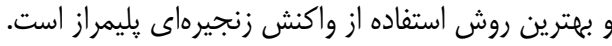

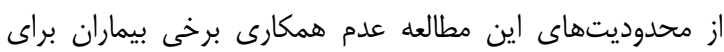

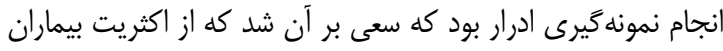

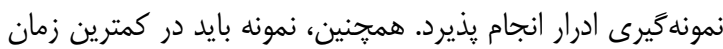

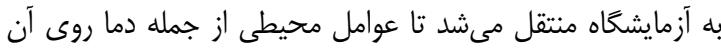

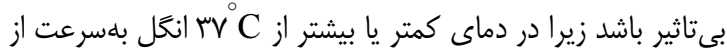

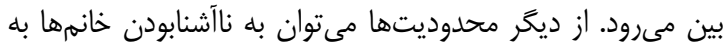

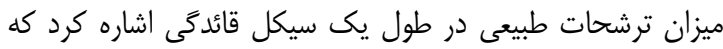

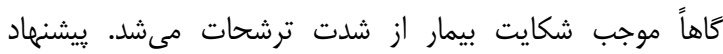

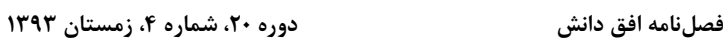




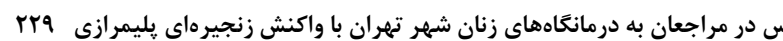
20- Dalimi Asl A, Shirbazoo Sh, Ghaffari far F, Jorjani A. Molecular detection of Trichomonas vaginalis using gene amplification of 18srRNA by PCR. Kowsar Medical Journal. 2008.3:179-84.

21- Katiyar SK, Edlind TD. Beta-tubulin genes of Trichomonas vaginalis. Mol Biochem Parasitol. 1994;64(1):33-42.

22- Secor WE, Meites E, Starr MC, Workowski KA. Neglected parasitic infections in the United States: trichomoniasis. Am J Trop Med Hyg. 2014;90(5):800-4.

23- Lawing LF, Hedges SR, Schwebke JR. Detection of trichomonosis in vaginal and urine specimens from women by culture and PCR. J Clin Microbiol. 2000;38(10):3585-8.

24- Anorlu R, Imosemi D, Odunukwe N, Abudu O, Otuonye M. Prevalence of trichomonas vaginalis in patients with vaginah discharge in hagos, Nigeria. J Natl Med Assoc. 2004;96(3):367-71.

25- López-Monteon A, Gómez-Figueroa FS, RamosPoceros G, Guzmán-Gómez D, Ramos-Ligonio A. Codetection of Trichomonas vaginalis and Candida albicans by PCR in urine samples in a low-risk population attended in a clinic first level in central Veracruz, Mexico. Biomed Res Int. 2013;281892.

26- Mazloumi AS, Namazi A, Sehhati F. prevalence \& risk factores of trichomoniasis among women in Tabriz. Iran J Clin Infect Dis. 2008;3(2):67-71.

27- Moshfe A, Hosseini S. Comparison of clinical \& microscopis diagnosis of trichomoniasis refferd to the Yasouj women clinics. J Armaghan e Danesh.2004;9(33):81-5.

28- Farahmand M, Rezaeian M. The prevalence of trichomoniasis in women attending family planning clinics using medium and direct observation in Tehran. J Med Pur. 1996;22:27-31. [Persian]

29- Rashdi S, Ziaee H, Yaqhoubi T. Health behaviors of women with trichomoniasis treatment centers in Sari. National Congress of Nursing and Midwifery Care. J School Nurs Midwifery Allied Kermanshah. 2002;1:50. [Persian] 30- Bakhshandeh S, Ghaemi A, Behnam pour N, Rezaee M. Etiologic agents of vaginal infections in women attending a gynecology clinic Daryan Hospital in Gorgan. J Secrets. 2003;3:58-64. [Persian]

31- Jamali R, Zaree kar B, Yousofi S, Ghazanchaee A. Comparison of visual sensitivity of direct microscopy and culture methods for detection of $\mathrm{T}$. vaginalis vaginalis referring to Tabriz health centers. J Lorestan Univ Med Sci. 2006;3:79-84. [Persian]

32- Mayta H, Gilman RH, Calderon MM, Gottlieb A, Soto $\mathrm{G}$, Tuero I, et al. $18 \mathrm{~S}$ ribosomal DNA-based PCR for diagnosis of Trichomonas vaginalis. J Clin Microbiol. 2000;38(7):2683-87.

33- Rabbani M, Saberi B, Mardanian F. Diagnosis of Trichomonas vaginalis infection by PCR method. J Med Sci Shahre kord. 2010;5:4-9. [Persian]

34- Sharifi I, Khatami M, Tahmores, Kermani E. Prevalence of Trichomonas Vaginalis in women referred to Vali-Asr polyclinic and the health center number 3 in Sirjan city. J Kerman Univ Med Sci.1994;1(3):125-32.

35- Sharbatdaran M, Shefaei Sh, Sami H, Haji Ahmadi M, Ramezanpour R, Mersadi N, et al. Comparison of clinical presentations, wet smear, Papanicolaou smear with Dorset's culture for diagnosis of Trichomonas Vaginalis in doubtful women to Trichomoniasis. J Babol Univ Med Sci. 2005;7(3)46-9.

36- Rosenberg MJ, Davidson AJ, Chen JH, Judson FN, Douglas JM. Barrier Contraceptives \& sexual transmitted Disease. Am J Public Health. 1992;82(5):669-74.
4- Miranda AE, Pinto VM, Gaydos CA. Trichomonas vaginalis infection among young pregnant women in Brazil. Braz J Infect Dis. 2014;18(6):669-71.

5- Valadkhani Z, Kazemi F, Assmar M, Amirkhani A, Esfandeari B, Lotfi $\mathrm{M}$, et al. Molecular diagnosis of trichomoniasis in negative samples examined by direct smear and culture. Iran J Parasitol. 2010;5(4):31-6.

6- Francis SC, Ao TT, Vanobberghen FM, Chilongani J, Hashim R, Andreasen A, et al. Epidemiology of curable sexually transmitted infections among women at increased risk for HIV in northwestern Tanzania: Inadequacy of syndromic management. PLoS One. 2014;15;9(7):101221.

7- Saleh AM, Abdalla HS, Satti AB, Babiker SM, Gasim GI, Adam I. Diagnosis of Trichomonous vaginalis by microscopy, latex agglutination, diamond's media, and PCR in symptomatic women, Khartoum, Sudan. Diagn Pathol. 2014;9;9:49.

8- Madico G, Quinn TC, Rompalo A, Mackee KT, Gaydos CA. Diagnosis of Trichomonas vaginalis infection by PCR using vaginal swab samples. $J$ Clin Microbiol. 1998;36(11):3205-10.

9- Paul H, Peter D, Pulimood SA, Abraham OC, Mathai E, Prasad JH, et al. Role of polymerase chain reaction in the diagnosis of Trichomonas vaginalis infection in human immunodeficiency virus-infected individuals from India (South). Indian J Dermatol Venereol Leprol. 2012;78(3):323-7.

10- Felleisen R. Comparative sequence analysis of $5.8 \mathrm{~S}$ rRNA genes and internal transcribed spacers (ITS) regions of trichomonadid protozoa. Parasitology. 1997;115(Pt 2):111-9. 11- Lin PR, Shaio MF, Liu JY. One-tube, nested-PCR assay for the detection of Trichomonas vaginalis in vaginal discharges. Ann Trop Med Parasitol. 1997;91(1):61-5.

12- van Der Schee C, van Belkum A, Zwijgers L, van Der Brugge E, O'neill EL, Luijendijk A, et al. Improved diagnosis of Trichomonas vaginalis infection by PCR using vaginal swabs and urine specimens compared to diagnosis by wet mount microscopy, culture, and fluorescent staining. J Clin Microbiol. 1999;37(12):4127-30.

13- Musatovova $\mathrm{O}$, Alderete JF. The Trichomonas vaginalis phenotypically varying $\mathrm{P} 270$ immunogen is highly conserved except for numbers of repeated elements. Microb Pathog. 1999; 27(2):93-104.

14- Mazloumi AS, Namazi A, Sehhati F. prevalence \& risk factores of trichomoniasis among women in Tabriz. Iran $\mathbf{J}$ Clin Infect Dis. 2008;3(2):67-71.

15- Bafghi AF, Aflatoonian A, Barzegar K, Ghafourzadeh $\mathrm{M}$, Nabipour S. Frequency distribution of trichomoniasis in pregnant women referred to health centers of Ardakan, Meibod and Yazd, Iran. Jondishapour J Microbiol. 2009;2(4):132-9.

16- Valadkhani Z, Asmar M, Esfandiari B, Amirkhani A, Hassan N, Lotfi M. Trichomoniasis in Asymptomatic patients. Iran J Public Health. 2008;37(3):113-7.

17- Valadkhani Z, Asmar M, Hassan N, Aghigh Z, Amirkhani A, Kazemi F, et al. Prevalence of trichomoniasis in high-risk behavior group women attending penitentiaries clinic of Tehran province. Giornale Italiano di Medicina Tropicale. 2010;14(1-4):43-6.

18- Matini M, Rezaie S, Mohebali M, Maghsood A, Rabiee S, Fallah M, Rezaeian M. Prevalence of Trichomonas vaginalis Infection in Hamadan City, Western Iran. Iran J Parasitol. 2012; 7(2):67-72.

19- Nourian A, Shabani N, Fazaeli A, Mousavinasab N. Prevalence of Trichomonas vaginalis in Pregnant Women in Zanjan, Northwest of Iran. Jundishapur $\mathrm{J}$ Microbiol. 2013;6(8):7258. 